\title{
The Clinical Outcomes of Stem Cell Therapy for Decompensated Liver Disease: A Systematic Review and Meta-Analysis
}

\author{
LIANGSHAN LV ${ }^{1 *}$ \\ Department of Vascular Surgery, ${ }^{1}$ Department of Gastroenterology, The First Affiliated Hospital of Xi'an Jiaotong University, \\ Xi'an 710061, China
}

Gu et al.: A Systematic Review on Stem Cell Therapy for Decompensated Liver Disease

\begin{abstract}
Worldwide, many patients with decompensated liver disease cannot get timely liver transplantation due to the shortage of the liver donors. In this case, stem cell therapy seems to be an alternative for patients with end stage liver disease. The aim of this article is to conduct a meta-analysis to evaluate the effectiveness of stem cell transplantation in patients with decompensated liver disease. Medline, Embase and Cochrane Library were searched for relevant studies. Only controlled trials were enrolled in this meta-analysis. Random effect model or fixed effect model will be used to analyze the collected data depending on the heterogeneity of the pooled studies. Review Manager 5.3 was used for statistical analysis. 8 publications involving 9 controlled studies were included in the final analysis. The studies were conducted in China, Iran, Egypt and India. Cell transplantation did not change the level of serum albumin and model for end stage liver disease score at $12 \mathrm{w}$ and $24 \mathrm{w}$. Furthermore, no matter at $12 \mathrm{w}$ or $24 \mathrm{w}$, the serum level of total bilirubin showed statistical decline. However, alanine transaminase, aspartate transaminase and prothrombin activity were improved significantly at $12 \mathrm{w}$, but this change was not obvious at $24 \mathrm{w}$. Stem cell transplantation showed some desirable outcomes in a relatively short term. However, many hepatic parameters did not last in the long term. Further studies are needed to explore the efficacy in patients with decompensated liver disease.
\end{abstract}

Key words: Stem cell transplantation, bone marrow, cell therapy, liver disease

Chronic liver disease is a widespread disease all over the world. With the advancement of this progressive disease, the conventional therapy will become invalid to the dysfunctional liver. Currently, the orthotopic liver transplantation (OLT) is the only feasible remedy to the end stage liver disease (ESLD). However, due to the shortage of organ donors and the expensive costs, many patients have to drop out from the transplantation waiting list. In this case, stem cell therapy seems to be an alternative therapy which is used in many pilot studies. Hematopoietic stem cells (HSCs) and mesenchymal stem cells (MSCs) are two commonly used stem cells in the clinical trials and show some promising perspective. Additionally, bone marrow mononuclear cells (BMMNCs) were also used in clinical trials and showed potential outlook. HSCs can be harvested not only from bone marrow aspiration but also peripheral blood after the injection of granulocyte colony stimulating factor
(G-CSF), so that the relatively easier accessibility over other cells is very desirable in the clinical application. Besides, MSCs also have some advantages, including the strong proliferative capacity even after expanded in vitro, high immune compatibility and low tumorgenesis risk. This meta-analysis aims to summarize the relevant clinical trials and evaluate the efficacy of the administration of these cells.

\section{MATERIALS AND METHODS}

\section{Literature search:}

Relevant clinical trials were collected by searching the Excerpta Medica database (EMBASE), Medical literature analysis and retrieval system online (MEDLINE) and the Cochrane library. This was done from the inception of the database to February 2018 by searching Medical subject headings (MeSH) terms 
combined with text words. The search term included (liver cirrhosis or ESLD or chronic liver disease) and (stem cell or HSCs or MSCs or MNCs). Additionally, the range of the articles was limited to human and controlled trials in the search filter. The titles and abstracts of the retrieved articles were examined. The selected papers were downloaded to view the full article. The references of selected publications were scrutinized for additional clinical trials.

\section{Inclusion and exclusion criteria:}

Inclusion criteria were as follows: Clinical studies using cell therapy for decompensated liver disease were included; studies contained at least one hepatic indices or prothrombin time (PT) in the articles; the type of the study was controlled trial which included one placebo or conventional treatment group. Studies were excluded if: they were one arm studies or case control studies; they were animal trials; the associated data cannot be extracted or calculated from the publications; ongoing studies; reviews or conference articles.

\section{Data extraction:}

The following information were extracted from the articles: name of the author, publication year, study design, sample size, gender and age, disease type, injection route, stem cell type, follow up time points, clinical symptoms, model for end-stage liver disease (MELD) scores, standard deviation (SD) and mean of the relevant biochemical blood indices (such as serum albumin (ALB) (g/l), alanine aminotransferase (ALT), aspartate aminotransferase (AST), total bilirubin (TB) $(\mathrm{mg} / \mathrm{dl}))$ in the control group and experimental group.

\section{Statistical method:}

Data analysis was performed with the Review Manager 5.3 from the Cochrane collaboration. The difference between experimental group and control group was defined by weighted mean difference (WMD). Heterogeneity was evaluated by $\mathrm{I}^{2}$ and $\mathrm{p}$ value, with $I^{2}>50 \%$ or $p<0.10$ meaning significant heterogeneity. If significant heterogeneity was presented, random effects model was used, otherwise fixed effects model with Mantel-Haenszel method was used to analyze the data.

\section{RESULTS AND DISCUSSION}

Our initial literature research generated 229 publications, of which 86 were duplications. After screening the titles and abstracts of the rest 143 articles, 115 were excluded due to irrelevant studies. 28 articles underwent the full text screening and only 8 were finally eligible to this meta-analysis. The general searching and screening process was showed in fig. 1. The article of Mohamadnejad in 2016 involved 2 studies $^{[1]}$. The characteristics of the included articles were presented in Table 1. The studies were from 4 countries (China, Egypt, India and Iran). In this meta-analysis, 6 out of 9 studies were randomized controlled trials. Moreover, 2 studies had cells infused through portal vein, 3 studies through hepatic artery and 4 studies through peripheral vein. In a study by Salama et al. in 2014, the injected
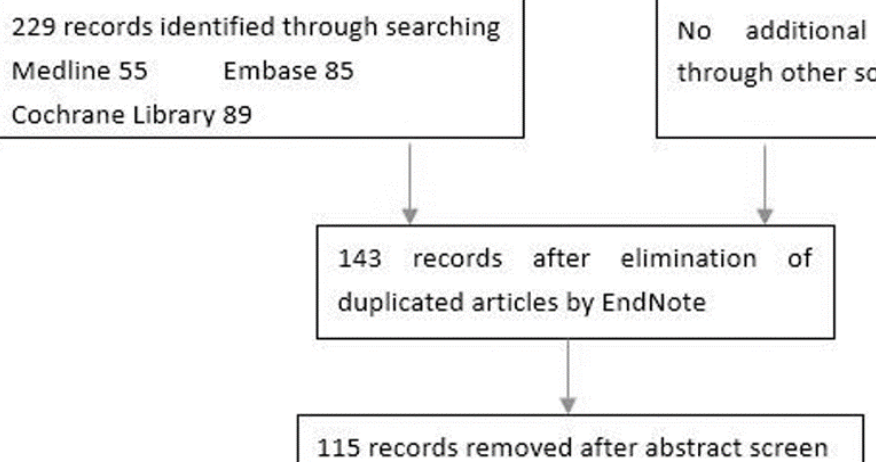

No additional records identified

through other sources

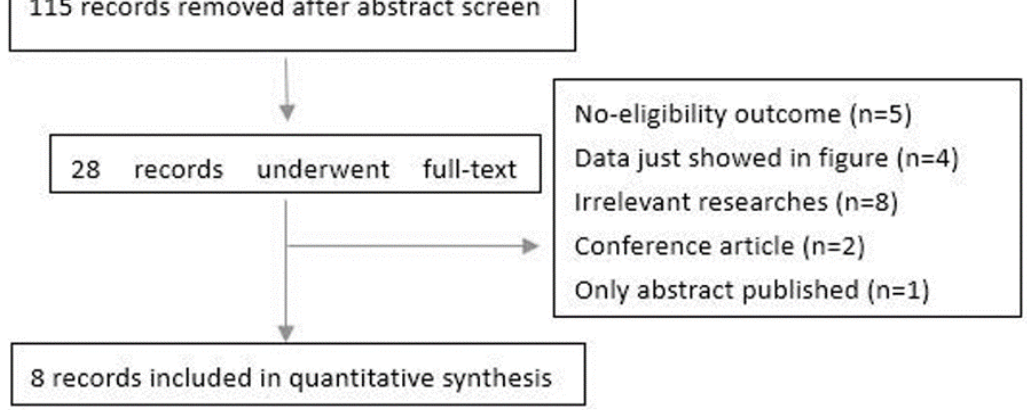

Fig. 1: Study flow diagram 
MSCs were differentiated from peripheral blood stem cells $^{[2]}$. None of the other studies used this kind of MSCs.

Biochemical indices (such as ALB, ALT, AST, TB, prothrobin activity (PTA)) that indicating the hepatic function and MELD score were used to evaluate the efficacy of the transplanted cells. The difference between the experimental group and controlled group was assessed at $12 \mathrm{w}$ and $24 \mathrm{w}$ due to their relatively common time points. With regard to the ALB level, a meta-analysis including 9 studies (fig. 2) showed that there was no significant difference between control group and experimental group at $12 \mathrm{w}$ (WMD: 1.44, $95 \%$ confidence intervals (CI): -0.19 to $3.08, \mathrm{p}=0.08$ ). At $24 \mathrm{w}$, the pooled data of included 6 studies also showed no improvement in the ALB level (WMD: $2.63,95 \% \mathrm{CI}:-0.67$ to $5.94, \mathrm{p}=0.12$ ).

Seven studies reported the TB level after stem cell transplantation at $12 \mathrm{w}$. The level of TB significantly decreased at $12 \mathrm{w}$ (WMD: $-0.89,95 \% \mathrm{CI}:-1.11$ to $-0.67, \mathrm{p}<0.00001)$. No heterogeneity was detected in the pooled data (fig. 3). Six studies reported the TB

TABLE 1: DESCRIPTION OF THE SELECTED STUDIES

\begin{tabular}{|c|c|c|c|c|c|c|}
\hline Study & Region & Sample size (a) & Disease & Infusion route & Cell type & Follow up \\
\hline Mohamadnejad et al. ${ }^{[1]}$ & Iran & 5 vs. 7 & $\begin{array}{c}\text { Decompensated liver } \\
\text { Cirrhosis }\end{array}$ & Portal vein & HSC (CD133+) & $3 \mathrm{mo}, 6 \mathrm{mo}$ \\
\hline Mohamadnejad et al. ${ }^{[1]}$ & Iran & 9 vs. 7 & $\begin{array}{c}\text { Decompensated liver } \\
\text { Cirrhosis }\end{array}$ & Portal vein & BM-MNCs & $3 \mathrm{mo}, 6 \mathrm{mo}$ \\
\hline Salama et al. ${ }^{[2]}$ & Egypt & 20 vs. 20 & HCV-induced ESLD & $\begin{array}{l}\text { Peripheral } \\
\text { vein }\end{array}$ & BM-MSCs & $2,4,12,24 \mathrm{w}$ \\
\hline Mohamadnejad et al. ${ }^{[5]}$ & Iran & 15 vs. 12 & $\begin{array}{c}\text { Decompensated liver } \\
\text { Cirrhosis }\end{array}$ & $\begin{array}{l}\text { Peripheral } \\
\text { vein }\end{array}$ & BM-MSCs & $3 \mathrm{mo}, 12 \mathrm{mo}$ \\
\hline Lin et al. ${ }^{[6]}$ & China & 38 vs. 16 & $\begin{array}{c}\text { Decompensated liver } \\
\text { Cirrhosis }\end{array}$ & $\begin{array}{l}\text { Peripheral } \\
\text { vein }\end{array}$ & UC-MSCS & $\begin{array}{l}1,2,4,8,12 \\
24,36,48 w\end{array}$ \\
\hline Salama et al. ${ }^{[7]}$ & Egypt & 90 vs. 50 & $\begin{array}{l}\text { End-stage } \\
\text { liver cirrhosis }\end{array}$ & $\begin{array}{l}\text { Peripheral } \\
\text { vein }\end{array}$ & $\begin{array}{l}\text { HSC (CD34+ } \\
\text {,CD133+) }\end{array}$ & $1,2,3,6 \mathrm{mo}$ \\
\hline Deng et al. ${ }^{[8]}$ & China & 33 vs. 35 & Hepatitis B Cirrhosis & Hepatic artery & $\mathrm{HSC}(\mathrm{CD} 34+)$ & $\begin{array}{c}0,12,24,36 \\
48 \mathrm{w}\end{array}$ \\
\hline Peng et al. ${ }^{[10]}$ & China & 53 vs. 105 & $\begin{array}{l}\text { Hepatitis B } \\
\text { Liver failure }\end{array}$ & Hepatic artery & BM-MSCs & Up to $192 \mathrm{w}$ \\
\hline Sharma et al. ${ }^{[11]}$ & India & 22 vs. 23 & $\begin{array}{c}\text { non-viral } \\
\text { decompensated } \\
\text { cirrhosis }\end{array}$ & Hepatic artery & $\mathrm{HSC}(\mathrm{CD} 34+)$ & $\begin{array}{c}1,2,3,4,8 \\
12 \mathrm{w}\end{array}$ \\
\hline
\end{tabular}

Note: BM-MSCs: Bone marrow mesenchymal stem cells; HCV: Hepatitis C virus ESLD: End stage liver disease; HSCs: Hematopoietic stem cells; UC-MSCs: Umbilical cord mesenchymal stem cell; Sample size (a): experimental numbers vs. control group numbers; BM-MNC: bone marrow derived mononuclear cell

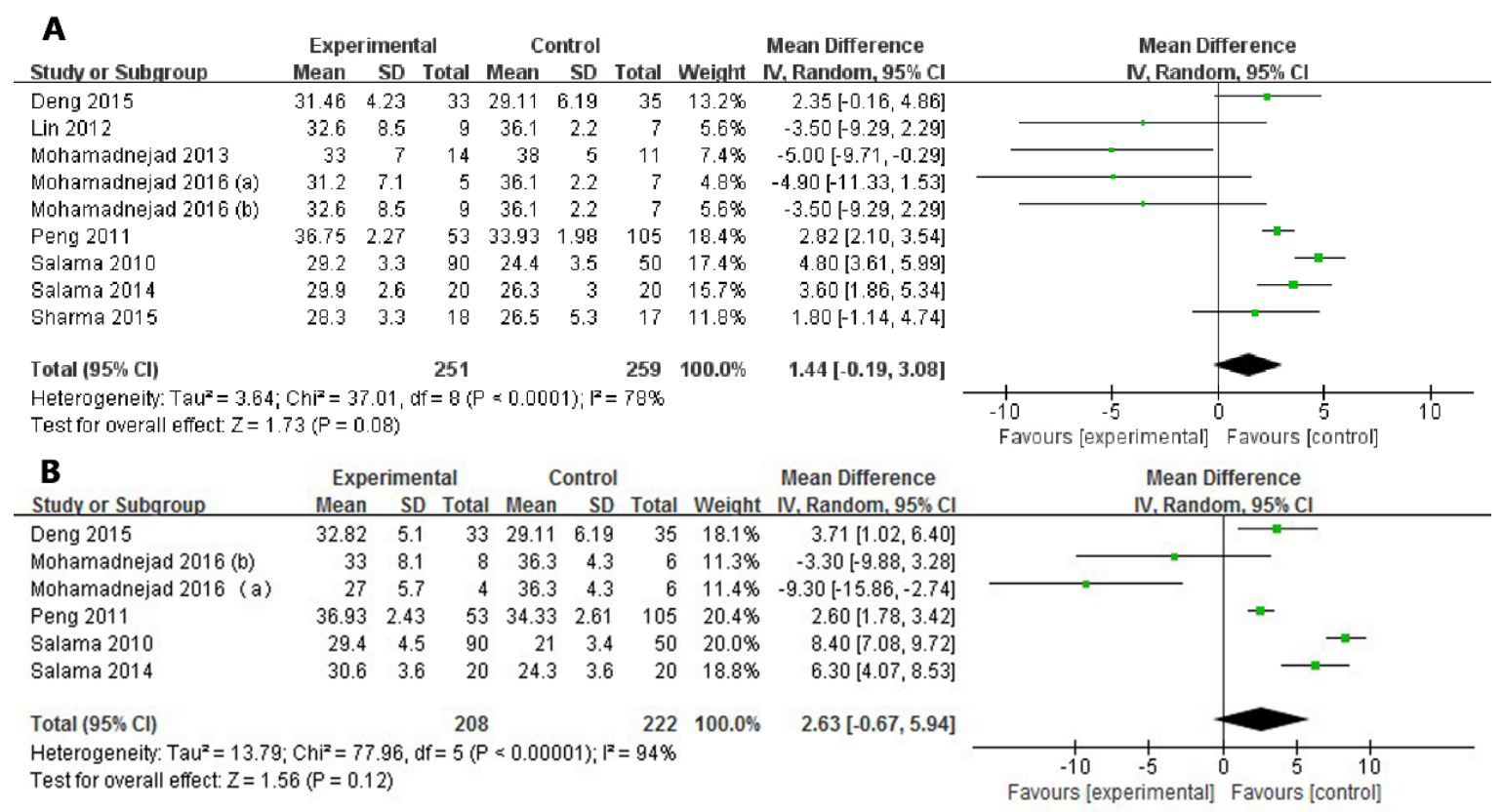

Fig. 2: The efficacy of cell transplantation on ALB at 12 w (A) and $24 \mathrm{w}$ (B) 
level at $24 \mathrm{w}$ and the heterogeneity is high $\left(\mathrm{I}^{2}=83 \%\right)$. As a result, random effect model was used and showed consistent improvement (WMD: -0.86, 95 \% CI: -1.60 to $-0.12, \mathrm{p}=0.02$ ).

Six studies and four studies assessed the MELD score, 12 and $24 \mathrm{w}$ after the administration of the stem cells (fig. 4). No matter at $12 \mathrm{w}$ (WMD: -1.44, $95 \% \mathrm{CI}$ : -3.81 to 0.92 ) or $24 \mathrm{w}$ (WMD: $-0.98,95 \% \mathrm{CI}:-3.53$ to 1.56 ), MELD score did not show any statistically improved outcome. In addition, the heterogeneity were high in 2 observational duration $\left(\mathrm{I}^{2}=83 \%\right.$ at $12 \mathrm{w}, \mathrm{I}^{2}=81 \%$ at $24 \mathrm{w})$.
Six studies and four studies evaluated the outcome of the ALT level in serum at $12 \mathrm{w}$ and $24 \mathrm{w}$ respectively (fig. 5) ${ }^{[3-5]}$. The pooled data showed a significant improvement (WMD: $-12.13,95 \% \mathrm{CI}:-15.51$ to -8.75 , $\mathrm{p}<0.00001)$ at $12 \mathrm{w}$ with no heterogeneity $\left(\mathrm{I}^{2}=32 \%\right)$. However, the desired outcome did not last for $24 \mathrm{w}$ (WMD: $3.73,95 \% \mathrm{CI}$ : -14.39 to $21.86, \mathrm{p}=0.69$ ).

AST level was reported by 5 studies or 3 studies depending on the time point evaluated (fig. 6) and it decreased statistically at $12 \mathrm{w}$ after treatment (WMD: $-12.62,95 \% \mathrm{CI}:-21.24$ to $-4.00, \mathrm{p}=0.004$ ). No heterogeneity was observed at $12 \mathrm{w}\left(\mathrm{I}^{2}=29 \%\right)$ or $24 \mathrm{w}\left(\mathrm{I}^{2}=33 \%\right)$. Nevertheless, the significant difference

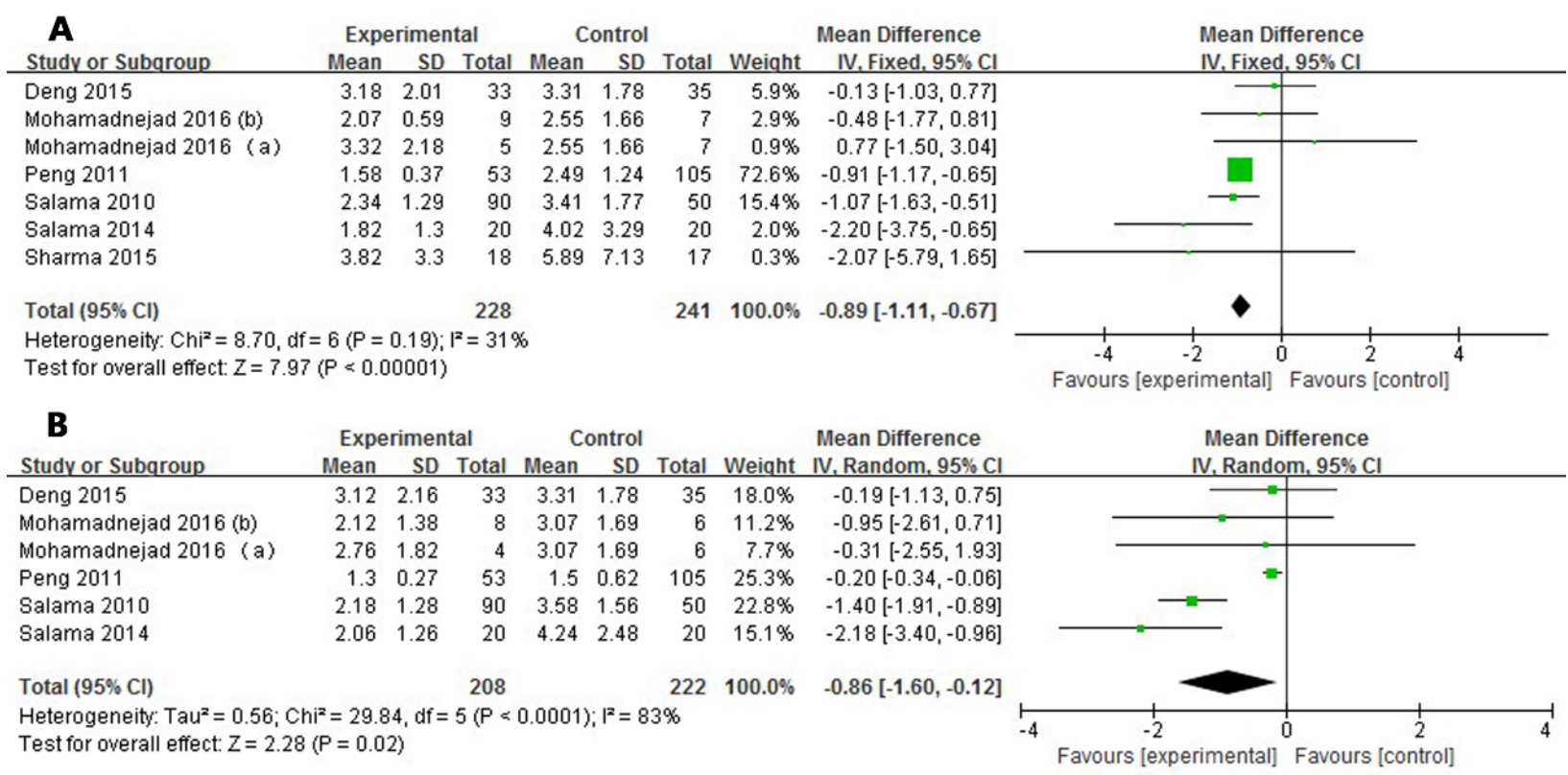

Fig. 3: The efficacy of cell transplantation on TB at 12 w (A) and 24 w (B)

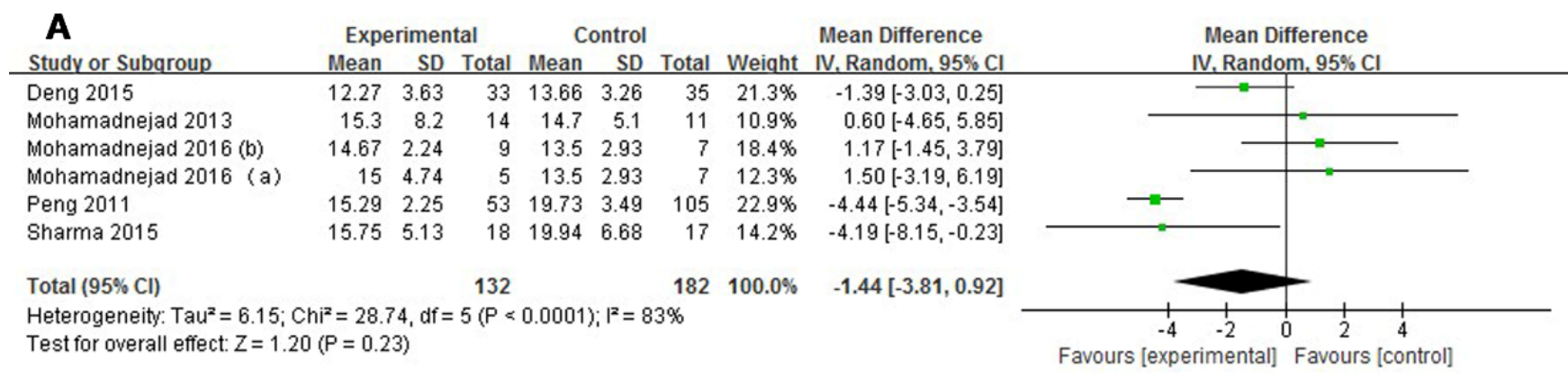

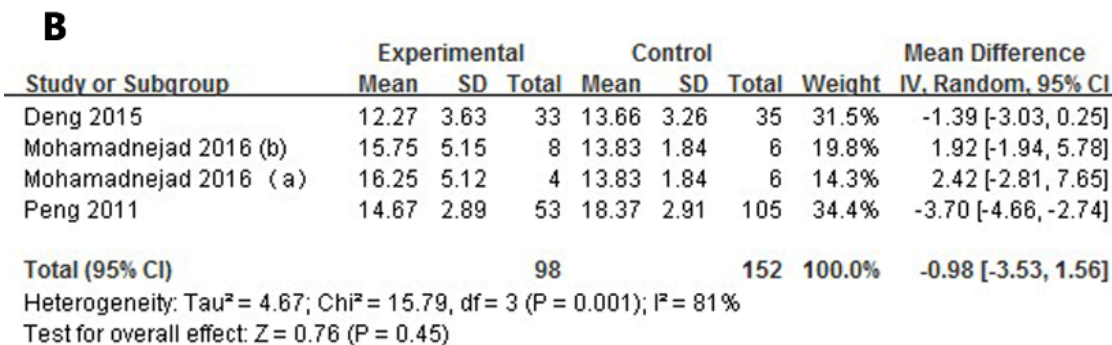

Fig. 4: The efficacy of cell transplantation on MELD score at $12 \mathrm{w}$ (A) and $24 \mathrm{w}$ (B) 
www.ijpsonline.com

\begin{tabular}{|c|c|c|c|c|c|c|c|c|c|c|c|c|}
\hline $\mathbf{A}$ & Expe & eriment & & & Control & & & Mean Difference & & Mean Di & Difference & \\
\hline Study or Subqroup & Mean & SD & Total & Mean & SD & Total & Weight & IV. Fixed, $95 \% \mathrm{Cl}$ & & IV, Fixed & d, $95 \% \mathrm{Cl}$ & \\
\hline Mohamadnejad 2013 & 54.6 & 44.9 & 14 & 53.4 & 40.6 & 11 & $1.0 \%$ & $1.20[-32.40,34.80]$ & & & & \\
\hline Mohamadnejad 2016 (b) & 44.78 & 24.68 & 9 & 55.25 & 63.07 & 7 & $0.5 \%$ & $-10.47[-59.90,38.96]$ & & & & \\
\hline Mohamadnejad 2016 (a) & 70.4 & 76.31 & 5 & 55.25 & 63.07 & 7 & $0.2 \%$ & $15.15[-66.44,96.74]$ & & & & \\
\hline Peng 2011 & 32.83 & 9.91 & 53 & 42.87 & 14.68 & 105 & $76.2 \%$ & $-10.04[-13.91,-6.17]$ & & 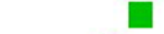 & & \\
\hline Salama 2010 & 42.8 & 16.1 & 90 & 63.5 & 23.7 & 50 & $21.1 \%$ & $-20.70[-28.06,-13.34]$ & & $\rightarrow$ & & \\
\hline Sharma 2015 & 39.44 & 19.02 & 18 & 49.18 & 66.59 & 17 & $1.1 \%$ & $-9.74[-42.59,23.11]$ & & & & \\
\hline Total $(95 \% \mathrm{Cl})$ & & & 189 & & & 197 & $100.0 \%$ & $-12.13[-15.51,-8.75]$ & & 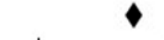 & & \\
\hline $\begin{array}{l}\text { Heterogeneity: } \mathrm{Chi}^{2}=7.38,0 \\
\text { Test for overall effect: } Z=7.0\end{array}$ & $\begin{array}{l}=5(P=c \\
(P<0.0\end{array}$ & $\begin{array}{l}0.19) ;\left.\right|^{2} \\
0001)\end{array}$ & $=32 \%$ & & & & & & -100 & $\begin{array}{c}1 \\
-50 \\
\text { s lexpe }\end{array}$ & 0 & $\begin{array}{c}1 \\
50 \\
\text { control] }\end{array}$ \\
\hline
\end{tabular}

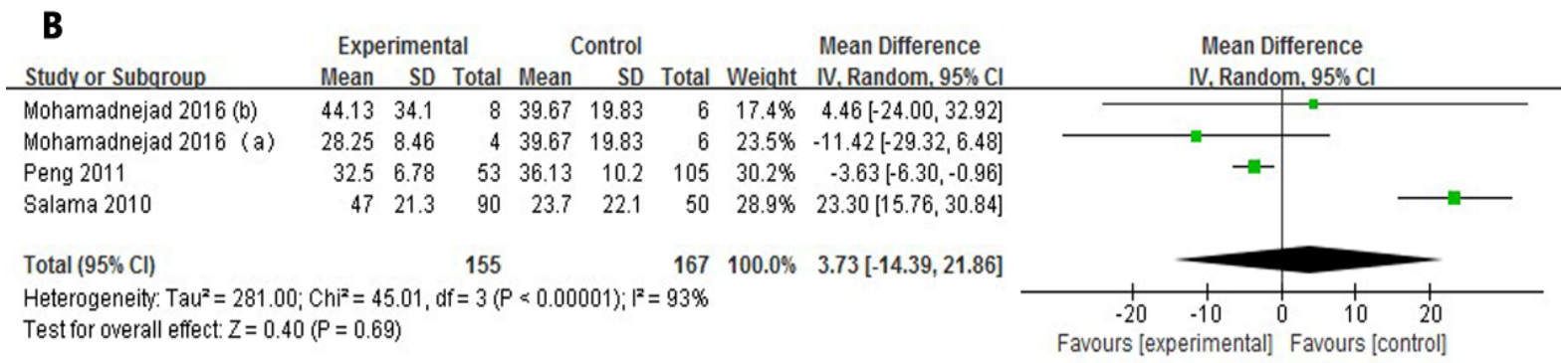

Fig. 5: The efficacy of cell transplantation on ALT at 12 w (A) and 24 w (B)

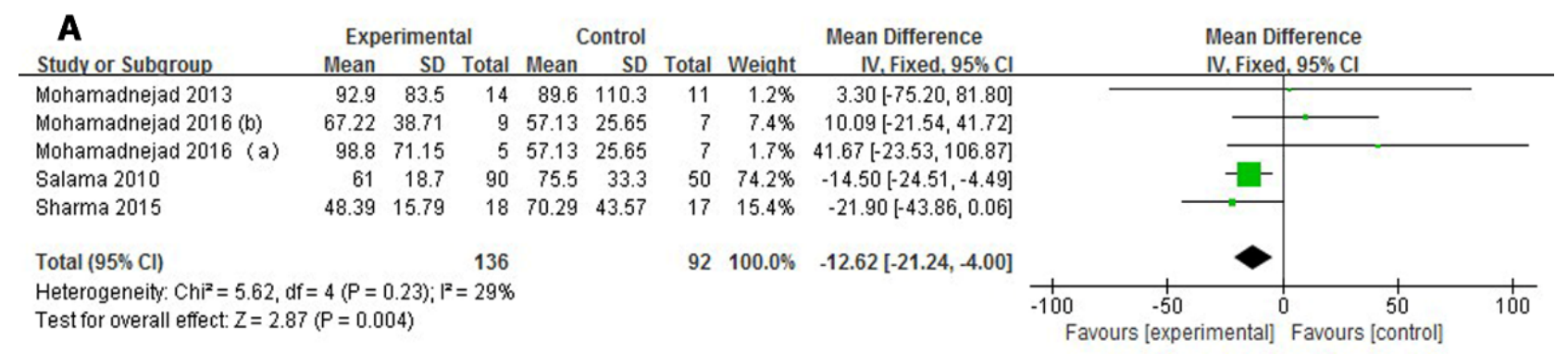

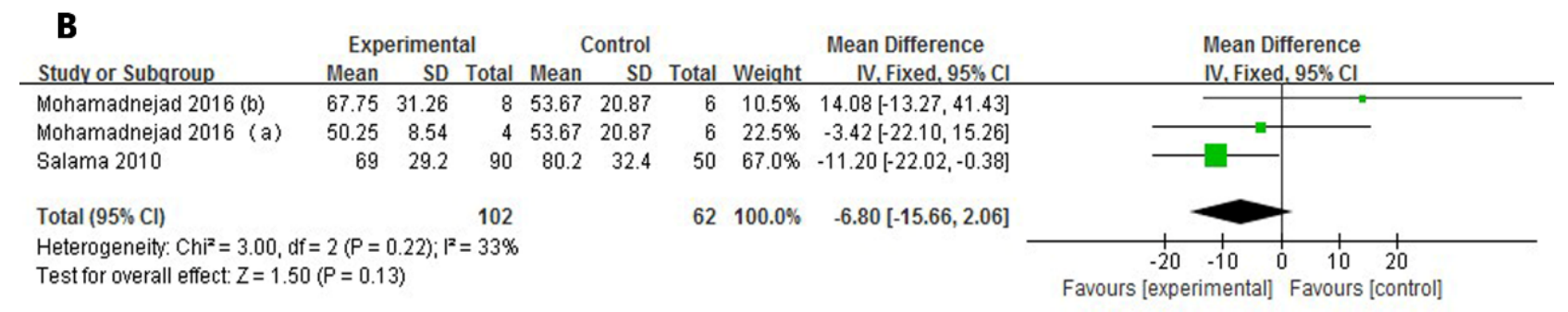

Fig. 6: The efficacy of cell transplantation on AST at 12 w (A) and 24 w (B)

of AST level disappeared at $24 \mathrm{w}$ (WMD: $-6.80,95 \%$ CI: -15.66 to $2.06, \mathrm{p}=0.13$ ).

Three and four studies assessed the difference of PTA at $12 \mathrm{w}$ and $24 \mathrm{w}$ after the transplantation (fig. 7). Due to the high heterogeneity among the studies $\left(\mathrm{I}^{2}=69 \%\right.$, $\mathrm{I}^{2}=90 \%$ ), a random effect model was used to analyze the data. The level of PTA was elevated in the experimental group at $12 \mathrm{w}$ and it showed a significant difference (WMD: 9.50, $95 \%$ CI: 3.57 to $15.42, \mathrm{p}=0.002$ ). Nevertheless, the promising outcome was not observed at $24 \mathrm{w}$ (WMD: 8.45, $95 \% \mathrm{CI}:-1.66$ to $18.56, \mathrm{p}=0.10$ ).

Chronic liver disease is a worldwide problem and OLT is the only remedy to the irreversible dysfunctional liver when it advances to ESLD. Recently, stem cell therapy becomes a promising alternative to this incurable disease. HSCs and MSCs are used in the clinical trials widely and in a relatively smaller scale, BM-MNCs are also applied to decompensated liver disease. BM-MNC contains not just one cell type, but a mixture of many types, including MSC, HSC, endothelial progenitor cell and stromal cell. After infusion of the BMMNCs, the contained non-HSCs may also contribute to the replenishment of the impaired hepatic function. Moreover, the fusion of HSC and hepatocyte can generates a hybrid cell which has the capacity to repair the injured liver tissue. This may exert some influence on the liver proliferation. The therapeutic rationale of MSCs is relatively clearer than HSCs in terms of hepatic repopulation. The main therapeutic effect of MSCs is via paracrine route by secreting some growth factors and cytokines, such as hepatic growth factor 
www.ijpsonline.com

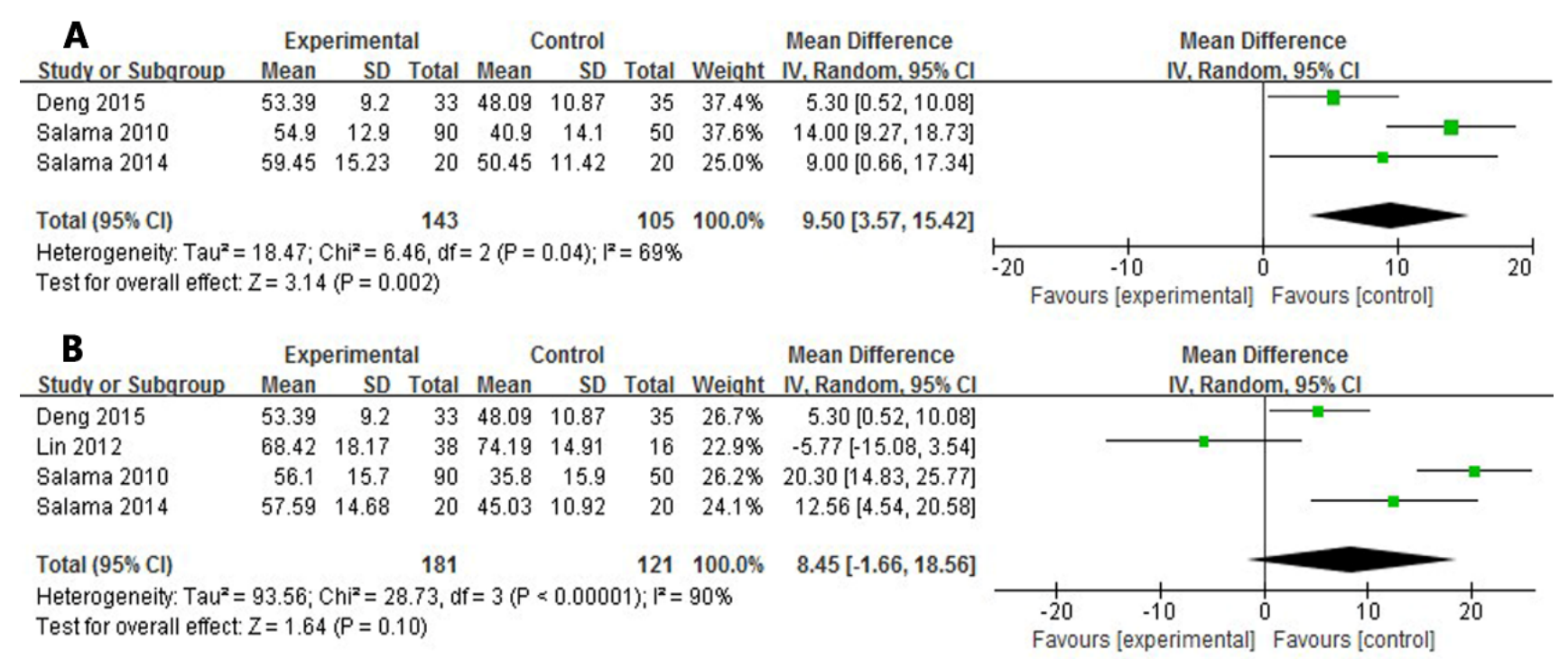

Fig. 7: The efficacy of cell transplantation on PTA at 12 w (A) and 24 w (B)

(HGF), interleukin-10 (IL-10), nerve growth factor (NGF). Additionally, the matrix metalloproteinases (MMP) expressed by MSCs have an anti-fibrotic effect of reducing collagen deposition for the impaired liver. Furthermore, human fetal liver derived stem cell can also regenerate the injured liver. Khan et al. reported that human fetal liver derived stem cell can statistically improve all the biochemical parameter and decrease the MELD score, but this is a one arm trial which cannot be included in this meta-analysis ${ }^{[3]}$.

In many cases, the efficacy of stem cell therapy is affected by many factors, including infused type and number of stem cells, injection route and frequency, efficacy of G-CSF and other adjuvant treatment. Some studies have showed that G-CSF can reduce the mortality rate of acute on chronic liver disease and severe alcoholic hepatitis. This is a confounder in many clinical trials because HSCs harvested from peripheral blood will inevitably use G-CSF to raise the concentration of HSCs. Moreover, the administration frequency is various in the enrolled studies. In this metaanalysis, the majority of studies applied stem cells only once, but in the studies by Lin et al. and Mohamadnejad et al., stem cells were repeatedly injected during the observational time point ${ }^{[5,6]}$. However, it is hard to limit the injection frequency in the inclusion and exclusion criteria due to the small number of the involved studies. Besides, the injection route may also exert an influence on the efficacy. A meta-analysis suggested that stem cells injected through hepatic artery showed better effectiveness than peripheral vein. El-Ansary reported that the injection of MSCs via peripheral vein or intrasplenic routes showed statistically different biochemical outcome (such as TB, creatinine) and MELD score ${ }^{[4]}$. Due to the influence of these potential factors, multicenter, large scale randomized clinical trial is needed to verify the efficacy of cell therapy both in the short term and long term.

There are some limitations in this meta-analysis. The publications involved may not be comprehensive enough to cover all related articles. In addition, it is hard to ignore some factors included in the studies, such as the various etiology and severity of the hepatic disease, the age of the enrolled patients (for that the older patients may have a lower capacity to improve liver function $)^{[7-11]}$. Importantly, the studies which used different cells via diverse injection routes were pooled together. These problems all contribute to the high heterogeneity in partial forest plots. Even the random effect model was used to analyze the information, interpreting the outcome should be cautious ${ }^{[12]}$.

In conclusion, this meta-analysis suggests that the outcome of stem cell transplantation for liver disease is relatively desirable in the short term $(12 \mathrm{w})$. However, significant difference of many hepatic indices did not last for $24 \mathrm{w}$. Therefore, this innovated intervention needs further studies to explore its efficacy and safety. Moreover, there are many problems confronted, such as the non-uniform approach of the adjuvant treatment, the uncertainty of the optimal injection routes and cell types, the ambiguous rationale of cell therapy for liver regeneration. In addition, it is imperative to track the infused cells in vivo to have a further understanding of the improved liver function. Overall, cell transplantation is a newly emerging therapy to provide an alternative modality for ESLD and may make a bridge for patients 
who cannot get timely liver transplantation.

\section{Authors' Contributions:}

Jingtao $\mathrm{Gu}$ and Liangshan Lv had contributed equally to this work.

\section{Conflicts of Interest:}

The authors declared no conflict of interest.

\section{REFERENCES}

1. Mohamadnejad M, Vosough M, Moossavi S, Nikfam S, Mardpour S, Akhlaghpoor S, et al. Intraportal infusion of bone marrow mononuclear or $\mathrm{CD} 133+$ cells in patients with decompensated cirrhosis: a double-blind randomized controlled trial. Stem Cells Transl Med 2016;5(1):87-94.

2. Salama H, Zekri AR, Medhat E, Al Alim SA, Ahmed OS, Bahnassy AA, et al. Peripheral vein infusion of autologous mesenchymal stem cells in Egyptian HCV-positive patients with end-stage liver disease. Stem Cell Res Ther 2014;5(3):12.

3. Khan AA, Shaik MV, Parveen N, Rajendraprasad A, Aleem MA, Habeeb MA, et al. Human fetal liver-derived stem cell transplantation as supportive modality in the management of end-stage decompensated liver cirrhosis. Cell Transplant 2010;19(4):409-18.

4. El-Ansary M, Mogawer S, Abdel-Aziz I, Abdel-Hamid S. Phase I trial: mesenchymal stem cells transplantation in end stage liver disease. Stem Cell 2010;1(2):22-33.

5. Mohamadnejad M, Alimoghaddam K, Bagheri M, Ashrafi M, Abdollahzadeh L, Akhlaghpoor S, et al. Randomized placebocontrolled trial of mesenchymal stem cell transplantation in decompensated cirrhosis. Liver Int 2013;33(10):1490-6.

6. Lin $\mathrm{H}$, Zhang Z, Shi $\mathrm{M}, \mathrm{Xu} \mathrm{RN}$, Fu JL, Geng H, et al. Prospective controlled trial of safety of human umbilical cord derived-mesenchymal stem cell transplantation in patients with decompensated liver cirrhosis. Chin J Hepatol 2012;20(7):48791.

7. Salama H, Zekri AR, Bahnassy AA, Medhat E, Halim HA, Ahmed OS, et al. Autologous CD34+ and CD133+ stem cells transplantation in patients with end stage liver disease. World $\mathrm{J}$ Gastroenterol 2010;16(42):5297.

8. Deng Q, Cai T, Zhang S, Hu A, Zhang X, Wang Y, et al. Autologous peripheral blood stem cell transplantation improves portal hemodynamics in patients with hepatitis B virus-related decompensated cirrhosis. Hepat Mon 2015;15(12):e32498.

9. Cao H, Zhang S, Weng W, Chen J, Xiong J, Zhang J, et al. The efficacy and long-term safety of autologous bone marrow stem cells transplantation in patients with hepatitis B virusassociated decompensated liver cirrhosis. Chin J Infect Dis 2017;35(12):719-24.

10. Peng L, Xie DY, Lin BL, Liu J, Zhu HP, Xie C, et al. Autologous bone marrow mesenchymal stem cell transplantation in liver failure patients caused by hepatitis B: short term and long term outcomes. Hepatology 2011;54(3):820-8.

11. Sharma M, Rao PN, Sasikala M, Kuncharam MR, Reddy C, Gokak V, et al. Autologous mobilized peripheral blood CD34+ cell infusion in non-viral decompensated liver cirrhosis. World J Gastroenterol 2015;21(23):7264-71.

12. Yangshu $\mathrm{C}$, Shi O, Tao C. Clinical efficacy of autologous bone marrow stem cell transplantation in treatment of hepatitis $\mathrm{B}$ patients with decompensated liver cirrhosis. J Clin Hepatol 2013:16(2):116-8.

This is an open access article distributed under the terms of the Creative Commons Attribution-NonCommercial-ShareAlike 3.0 License, which allows others to remix, tweak, and build upon the work non-commercially, as long as the author is credited and the new creations are licensed under the identical terms

This article was originally published in a special issue, "Evolutionary Strategies in Biomedical Research and Pharmaceutical Sciences" Indian J Pharm Sci 2021:83(3) Spl issue;211-217 